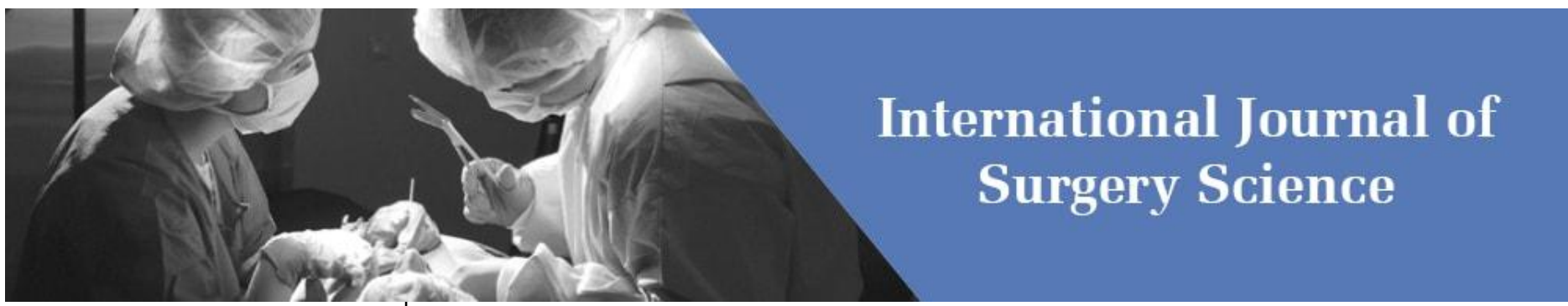

E-ISSN: 2616-3470

P-ISSN: 2616-3462

(C) Surgery Science

www.surgeryscience.com

2020; 4(3): 98-101

Received: 14-05-2020

Accepted: 17-06-2020

Dr. Goutham Kompally

Assistant Professor, Department of

General Surgery, Kamineni

Institute of Medical Sciences,

Narkatpally, Nalgonda District,

Telanagana, India.

Dr. K Suresh Kumar

Associate Professor, Department of

General Surgery, Kamineni

Institute of Medical Sciences,

Narkatpally, Nalgonda District,

Telanagana, India.

Corresponding Author:

Dr. K Suresh Kumar

Associate Professor, Department of

General Surgery, Kamineni

Institute of Medical Sciences,

Narkatpally, Nalgonda District,

Telanagana, India.

\section{A clinical study of obstructive jaundice secondary tocholedocholithiasis}

\section{Dr. Goutham Kompally and Dr. K Suresh Kumar}

DOI: https://doi.org/10.33545/surgery.2020.v4.i3b.478

\section{Abstract}

Background: Jaundice is known to mankind since time immemorial. The general surgeon frequently encounters obstructive jaundice. Obstructive jaundice in a patient can be due to intrahepatic or extrahepatic obstruction. Abdominal ultrasound is the preferred first radiological examination in most patients in whom biliary tract obstruction is suspected.

Aim \& Objectives: This study is done to know the incidence of obstructive jaundice due to choledocholithiasis in my hospital, its clinical presentation, role of ultrasound in diagnosing such cases and different modalities of treatment instituted at Kamineni Institute of Medical Sciences, Hyderabad.

Methods: This is a study of 20 patients of obstructive jaundice secondary to choledocholithiasis who presented to Kaminenei Institute of Medical Sciences between June 2017 to June 2019. These patients subsequently underwent surgical interventions. All these patients have been thoroughly assessed both preoperatively and post-operatively as per the proforma.

Results: The hospital based incidence of obstructive jaundice secondary to choledocholithiasis was $0.14 \%$. Most of the patients were females with ratio of 16:4. Patients presented with following symptoms in decreasing order of frequency. Jaundice (100\%), pain abdomen (90\%), dyspepsia/nausea/vomiting (45\%), itching (30\%), loss of appetite and weight (25\%), fever with chills and rigors (20\%), steatorrhoea (5\%) and mass abdomen $(5 \%)$ of the cases. The ultrasound detected stones in CBD 17 cases $(85 \%)$ and dilated CBD in all 20 cases (100\%). Choledocholithiasis was found in 11 cases. Choledocholithiasis and cholelithiasis was present in four cases. While one case of choledocholithiasis with CBD stricture was encountered during the study. In most of the cases the operative procedure was choledochoduodenostomy (45\%) followed by choledochotomy with T-tube drainage 35\%. Choledocho-jejunostomy and Transduodenal sphincter procedure was done in two case each. In all twenty cases cholecystectomy was performed. All the cases were followed up for a varying period from 1-6 months with no complaints.

Conclusion: In the past bile duct surgery was accompanied by significant morbidity and mortality, with recent advances in supportive care, the numbers are decreasing. Obstructive jaundice secondary to gallstones in the CBD remains the commonest cause Obstructive jaundice patients are also prone for infections because of poor liver function, which can affect immunity. It is also important to identify individual risk factors in all the patients undergoing biliary tract surgery. Even though this is an era of laparoscopic CBD exploration, places where the technology and expertise are not available, open, internal and external biliary drainage procedures are still followed with good results.

Keywords: Jaundice, Cholecystectomy, Choledocho- duodenostomy, Choledocho-jejunostomy, Laparoscopic and Ultrasound.

\section{Introduction}

Surgical jaundice is defined as a condition where the outflow of bile is obstructed anywhere from the intrahepatic biliary canaliculi up to the opening of common bile duct at ampulla of Vater.

The general surgeon frequently encounters obstructive jaundice. Obstructive jaundice in a patient can be due to intrahepatic or extrahepatic obstruction.

Extra hepatic obstruction is commonly due to stones. It also could be due to growths obstructing the common bile duct commonly referred to as malignant jaundice.

Recent advances in imaging techniques and with improvement in the field of anaesthesia, management of surgical jaundice has taken a new turn. With advances in procedures like ERCP and MRCP a surgical jaundiced patient can be managed more confidently.

Obstructive jaundice due to malignant growths always poses a challenge to the surgeon as the patient is usually in his terminal stages. 


\section{Objectives}

1. To know the incidence of obstructive jaundice secondary to choledocholithiasis in my hospital.

2. To study its clinical manifestations.

3. To study the role of ultrasound in this condition.

4. To study the various modalities of treatment at Kamineni Institute of Medical Sciences, Narkatpally.

\section{Materials and Methods}

\section{a. Source Of Data}

Patients admitted under various surgical units from June 2017 to June 2019, at Kamineni Institute of Medical Sciences, Narkatpally. Only the cases with surgical jaundice secondary to choledocholithiasis are studied in detail according to the proforma given.

A study was carried out on these jaundiced patients. The incidence of jaundice in total surgical admission of 14, 526, i.e. $0.21 \%, 30$ jaundice patients were admitted, out of which 20 patients with jaundice secondary to choledocholithiasis were studied in detail.

\section{Method of Collection of Data}

This is a study of twenty (20) patients who presented with jaundice to the above hospitals between June 2017 to June 2019 who subsequently underwent surgical intervention. All these patients have been thoroughly assessed both preoperatively and postoperatively as per the proforma. All the patients have been investigated appropriately to rule out medical causes for the jaundice. Complications were documented. Photographic documentation has been done wherever possible. Where patients underwent surgical intervention, any tissue removed was subjected for histopathological examination.

\section{Results}

Twenty patients were involved in this clinical study wherein surgical intervention was necessary to relieve the jaundice.

\section{Age and Sex Distribution}

The age varied from 18 years to 65 years. The age and sex based analysis is given below

Table 1: Age and sex distribution

\begin{tabular}{|c|c|c|}
\hline Age (years) & Male & Female \\
\hline $10-20$ & 1 & - \\
\hline $21-30$ & 2 & 3 \\
\hline $31-40$ & - & 3 \\
\hline $41-50$ & - & 3 \\
\hline $51-60$ & 1 & 3 \\
\hline $61-70$ & - & 4 \\
\hline Total & 4 & 16 \\
\hline
\end{tabular}

Table 2: Showing the symptoms distribution

\begin{tabular}{|c|c|c|}
\hline Symptoms & Number of cases & $\mathbf{\%}$ \\
\hline Jaundice & 20 & 100 \\
\hline Pain abdomen & 18 & 90 \\
\hline Main abdomen & 1 & 05 \\
\hline Itching & 6 & 30 \\
\hline Nausea/vomiting & 9 & 45 \\
\hline Fever with chills and rigor & 4 & 20 \\
\hline Loss of appetite \& weight & 5 & 25 \\
\hline Steatorrhoea & 1 & 5 \\
\hline
\end{tabular}

Incidence of Presenting Symptoms

Jaundice: It was present in all twenty cases (100\%).

Pain abdomen: It was present in 18 (90\%) it was colicky in 9 cases. More commonly it was dull aching, continuous pain in epigastrium and right hypochondrium. Few had pain radiating to the back.

Mass abdomen: It was present in $1(5 \%)$ case, which was a case of double impaction of stones, one at cystic duct and other at terminal CBD.

Itching: Present in $6(30 \%)$ cases.

Dyspepsia/Nausea/Vomiting: Present in 9 (45\%) cases.

Fever with chills and rigors: Present in $4(20 \%)$ cases.

Loss of appetite and weight: Present in 5 (25\%) cases.

Bowel habits: None of the cases had specific bowel complaints. On detailed enquiring 2 gave history of diarrhea and rest had normal habits. Steatorrhoea was present in $1(5 \%)$ cases.

Past history: Two cases had previous attacks of jaundice, which was treated conservatively. One patient had undergone cholecystectomy, 3 patients had diabetes mellitus and 2 were hypertensive.

Personal history: Three male patients were habituated to smoking and alcohol consumption. Sleep was disturbed in 12 cases.

Family history: No relevant family history of jaundice, congenital disease, malignancy, etc. could be obtained from any of the patients.

General physical examination: Out of 20 cases, 2 were emaciated at the time of admission. All the 20 cases were jaundiced. Pallor was present in 10 cases.

Per abdomen: No organomegaly. Right hypochondrium tenderness was present in 17 cases and in epigastrium in 3 cases. Mass in the right hypochondrium was present in $1(3 \times 2 \mathrm{~cm})$, smooth, globular, just below the costal margin. Free fluid was present in none.

\section{Investigations}

Hemoglobin varied between 5-13 gm\%. Total count varied between 5000-11000. All the components in the differential count were within normal limits. ESR was raised in three cases. Serum bilirubin was elevated in all the cases. The total bilirubin was between $8-20 \mathrm{mg} \%$, average being $13 \mathrm{mg} \%$, the direct portion being the predominant one. Serum protein was within normal limits. Alkaline phosphatase was elevated in all cases. It varied from upper limit of normal to about 5 times the upper limit. SGOT and SGPT were moderately raised in three cases.

\section{Radiological Studies}

Abdominal ultrasound was the main diagnostic procedure in this study. 
Ultrasound Findings

Table 3: Ultrasound findings

\begin{tabular}{|c|c|c|}
\hline Findings & Number of cases & Percentage \\
\hline Dilated CBD & 20 & 100 \\
\hline IHBD & 15 & 75 \\
\hline Stones in CBD & 14 & 70 \\
\hline GB distension & 2 & 10 \\
\hline
\end{tabular}

All the cases had dilated common bile duct. In 15 cases stones in the common bile duct could be visualized. IHBD was present in 14 cases. Gall bladder was distended in 1 case. This was the case of double impaction of stones, one at cystic duct and the other at the lower $1 / 3^{\text {rd }}$ of CBD.

Other investigations done were X-ray abdomen, ERCP, operative cholangiogram and CT. In one case X-ray showed multiple stones in the gall bladder and common bile duct. ERCP was done in 1 case and it showed stricture of liver $1 / 3^{\text {rd }}$ of common bile duct with stones.

\section{Diagnosis}

Table 4: Diagnosis

\begin{tabular}{|c|c|}
\hline Diagnosis & Number of cases \\
\hline Cholelithiasis and choledocholithiasis & 4 \\
\hline Choledocholithiasis & 15 \\
\hline Choledocholithiasis with CBD stricture & 1 \\
\hline
\end{tabular}

\section{Treatment Given}

All the cases were prepared adequately for a period varying from 2-4 weeks before surgery. Vit. $\mathrm{K}$ was administered twice daily starting 3 days before surgery.

In the postoperative management, adequate intravenous fluids were given. Urine output was maintained adequately. T-tube was kept for 15-30 days. After doing a T-tube cholangiogram to rule out missed stones the T-tube was removed. In our study there was no case of missed stones.

In all the cases aspirated bile was sent for culture and sensitivity. If it was positive then proper antibiotics were started.

Resected specimens were also sent for histopathological examination.

\section{Operative Procedures Performed}

Table 5: Operative procedures performed

\begin{tabular}{|c|c|}
\hline Procedure & $\begin{array}{c}\text { Number of } \\
\text { cases }\end{array}$ \\
\hline Cholecystectomy with choledochoduodenostomy & 9 \\
\hline $\begin{array}{c}\text { Cholecystectomy with choledochotomy and T-tube } \\
\text { drainage }\end{array}$ & 7 \\
\hline Cholecystectomy with choledochojejunostomy & 2 \\
\hline $\begin{array}{c}\text { Cholecystectomy with trans duodenal sphincterotomy } \\
\text { and stone retrieval }\end{array}$ & 2 \\
\hline
\end{tabular}

$9(45 \%)$ cases of choledocholithiasis were treated with cholecystectomy with choledochoduodenostomy. 7 (35\%) cases of cholethiasis and choledocholithiasis were treated with cholecystectomy and choledochotomy and T-tube drainage. For two case of common bile duct stricture with CBD stones, cholecystectomy with choledochojejunostomy was done. Two $(10 \%)$ cases had wound sepsis, which was treated with change of antibiotics after doing culture and sensitivity.

All the cases have been followed up for varying period from 1-6 months with no complaints.

\section{Discussion}

Surgical jaundice is one of the commonest conditions encountered by general surgery. Thirty patients presented with jaundice due to various causes. The hospital based incidence being $0.21 \%$. The jaundiced patients secondary to choledocholithiasis were 21 . The hospital based incidence being $0.14 \%$. Out of these, 20 cases of obstructive jaundice secondary to choledocholithiasis were studied in detail, regarding their manifestations, the role of ultrasound in diagnosing such cases and the various modalities of treatments offered at Kamineni Institute of Medical Sciences.

Jaundice is rarely a surgical emergency. So, when the clinician has completed the initial examination of the jaundiced patient, the correct diagnosis may be obvious of the findings or may be such that a definite diagnosis cannot be established. If the diagnosis is doubtful and in the absence of cholangitis, with unremitting fever and toxic reaction, it is wise to employ a period of observation. During this time the history, physical findings and liver function tests should be frequently reviewed in an attempt to establish the correct diagnosis. Unless, there is a clear cut indication, antibiotics, should not be used. Serum alkaline phosphatase and bilirubin will be raised in all obstructive jaundice cases and so it was in all our cases.

Prolong prothrombin time with reversal to normal after the administration of vit. $\mathrm{K} 10 \mathrm{mg}$ for 3 days proves the presence of obstructive jaundice.

In our study as compared to other work done by various authors we have found that obstructive jaundice secondary to common bile duct obstruction due to gall stones remains the commonest cause. So in our study we have analysed various methods of dealing with obstruction secondary to gallstones.

Though several methods have been attempted in dealing with the gallstones in the common bile duct, choledochotomy with $\mathrm{T}$ tube drainage remains the safest method in dealing with common bile duct stones with less morbidity, followed by choledochoduodenostomy.

All the patients in our study were followed up for varying period from 1-6 months. Patients with common bile duct obstruction due to gall stones and who had common bile duct exploration done were doing fairly well without any postoperative complications like stricture and recurrent stone formation.

We have compared our study with studies done by Agrawal et al., ${ }^{[1]}$ Nadkarni et al. ${ }^{[2]}$ and M.H.K. Crumplin et al., ${ }^{[3]}$ which has been summarized as follows.

Table 6: Presenting symptoms and signs

\begin{tabular}{|c|c|c|c|}
\hline Symptoms & $\begin{array}{c}\text { Agrawal } \text { et } \\
\text { al. }{ }^{\left[{ }^{[1]}\right.}\end{array}$ & $\begin{array}{c}\text { Nadkarni } \text { et } \\
\boldsymbol{a l}^{\left[{ }^{[2]}\right.}\end{array}$ & $\begin{array}{c}\text { Present } \\
\text { study }\end{array}$ \\
\hline Jaundice & 100 & 100 & 100 \\
\hline Pain abdomen & 79.1 & 53.8 & 90 \\
\hline Mass abdomen & 58 & 92.3 & 5 \\
\hline Itching & 50 & 73.1 & 30 \\
\hline Dyspepsia/Nausea/Vomiting & 70.9 & 88.5 & 45 \\
\hline Fever with chills and rigor & 12.5 & 53.8 & 20 \\
\hline Loss of appetite and weight & 66.7 & 19.2 & 25 \\
\hline Steatorrhoea & 41.7 & 92.3 & 5 \\
\hline
\end{tabular}

As can be seen from the table jaundice was the main presenting symptom in all the studies. In the study of Agrawal et al. and Nadkarni et al. dyspepsia/nausea/ vomiting was the other major presenting symptom. In our study it was pain abdomen, dyspepsia/nausea/vomiting and itching. 


\section{The Ultrasonic Diagnosis of Choledocholithiasis}

The role of ultrasound in diagnosis of choledocholithiasis in jaundiced patients, when compared with the series of Mesterenko IuA et al., ${ }^{[4]}$ we got the following results.

Table 8: Ultrasonic diagnosis

\begin{tabular}{|c|c|c|}
\hline & $\begin{array}{c}\text { Mesterenko IuA } \text { et al. } \\
{[4]}\end{array}$ & $\begin{array}{c}\text { Present } \\
\text { study }\end{array}$ \\
\hline Total number of cases studied & 162 & 20 \\
\hline $\begin{array}{c}\text { Ultrasound visualization of CBD } \\
\text { stones }\end{array}$ & $139(86 \%)$ & $17(85 \%)$ \\
\hline
\end{tabular}

As seen from the table that ultrasound scan picked up $86 \%$ and $80 \%$ of cases of jaundice with choledocholithiasis in Mesterenko IuA et al. study and present study respectively.

So it is suggested that it is obligatory to perform ultrasound examination in diseases of extrahepatic biliary ducts.

\section{Surgical Procedures Performed}

Table 9: Surgical procedures performed

\begin{tabular}{|c|c|c|}
\hline Procedure (along with cholecystectomy) & $\begin{array}{c}\text { M.H.K. } \\
\text { Crumplin } \text { et al. } \\
{[3]}\end{array}$ & $\begin{array}{c}\text { Present } \\
\text { study }\end{array}$ \\
\hline $\begin{array}{c}\text { Supradeudenal duct exploration and T-tube } \\
\text { drainage }\end{array}$ & $57(36 \%)$ & $8(40 \%)$ \\
\hline $\begin{array}{c}\text { Supradeudenal duct exploration and } \\
\text { choledochodeudenostomy }\end{array}$ & $57(36 \%)$ & $4(20 \%)$ \\
\hline Choledochodeudenostomy & $2(1.25 \%)$ & $6(30 \%)$ \\
\hline $\begin{array}{c}\text { Supradeudenal duct exploration and } \\
\text { transdeudenal sphincter procedures }\end{array}$ & $40(25 \%)$ & $1(5 \%)$ \\
\hline Transdeudenal sphincter procedures & $2(1.25 \%)$ & 0 \\
\hline Other combinations & $2(1.25 \%)$ & $1(5 \%)$ \\
\hline
\end{tabular}

The main procedures for benign conditions causing jaundice are cholecystectomy with choledochotomy and T-tube drainage, and cholecystectomy with choledochotomy and choledochoduodenostomy. Supraduodenal duct exploration and transduodenal sphincter procedure was carried out in one patient with CBD stone at the ampula of vator, as against 40 cases in M.H.K. Crumplin et al. series. One patient underwent cholecystectomy with duct exploration and choledochojejunostomy.

\section{Conclusion}

1. Bile duct surgery was accompanied by significant morbidity and mortality, with recent advances in supportive care, the numbers are decreasing.

2. Obstructive jaundice secondary to gallstones in the common bile duct is the commonest cause.

3. In case of surgical jaundice that is progressive it is very important to decompress the biliary tree as soon as possible because it may seriously affect the liver function and renal function.

4. Obstructive jaundice patients who are being taken up for surgery have to be thoroughly assessed preoperatively regarding their nutritional status and also improve liver function by infusing glucose and also correct any bleeding abnormalities by giving vit. K. injections.

5. Obstructive jaundice patients are also prone for infections because of poor liver function, which can affect immunity.

6. It is also important to identify individual risk factors in all the patients undergoing biliary tract surgery.

7. Over the past decade there have been many technological armamentarium of imaging and diagnostic procedures, which have radically changed the approach to the management of surgical jaundice. As we have seen from our study ultrasound remains the cheapest, safest and the most reliable diagnostic tool in the management of surgical jaundice.

8. Even in this era of laparoscopic CBD exploration, places where latest technology and expertise are not available, open procedures are still safe, feasible and single- stage option for the management of CBD stones with good results in terms of morbidity and mortality.

\section{Acknowledgment}

The author thankful to Department of Surgery for providing all the facilities to carry out this work.

\section{Conflict of Interest \\ None}

\section{References}

1. Agrawal JB, Patel RA. Surgical management of obstructive jaundice. J Ind Med Ass June 1974; 62(12):414-416.

2. Nadkarni KM, Jahagirdar RR, Kagzi RS, Pinto AC, Bhale Rao RA. Surgical obstructive jaundice - A study of 26 cases. J Postgraduate Medicine. 1981; 27(1):33-39.

3. Crumplin MKH, Jenkinson LR Kassab, Whitaker CM, AlBoutiahi FH. Management of gall stones in a district general hospital. Br Jr of Surgery June. 1985; 72:428-432.

4. Mesterenko IVA, Shapovaliants SG, Mikkailusov SV, Drozdov GE. The ultrasonic diagnosis of choledocholithiasis. Khirurgiia (Mosk) January 1993; 1:3743. 